\title{
DESIGN AND CELLULAR STUDIES OF A CARBON NANOTUBE-BASED DELIVERY SYSTEM FOR A HYBRID PLATINUM-ACRIDINE ANTICANCER AGENT
}

Cale D. Fahrenholtz ${ }^{\mathrm{a}}$, Song Ding ${ }^{\mathrm{b}}$, Brian W. Bernish ${ }^{\mathrm{a}}$, Mariah L. Wright ${ }^{\mathrm{b}}$,Ye Zheng, Mu Yang ${ }^{\mathrm{b}}$, XiyuanYao ${ }^{\mathrm{b}}$, George L. Donati ${ }^{\mathrm{b}}$, Michael D. Gross ${ }^{\mathrm{b}}$, Ulrich Bierbach ${ }^{\mathrm{b}, \mathrm{c}}$, Ravi Singh ${ }^{\mathrm{a}, \mathrm{c}_{*}}$

a Department of Cancer Biology, Wake Forest School of Medicine, Winston-Salem, NC, 27157, USA;

${ }^{\mathrm{b}}$ Department of Chemistry, Wake Forest University, Winston-Salem, NC, 27109, USA;

${ }^{\mathrm{c} C o m p r e h e n s i v e ~ C a n c e r ~ C e n t e r ~ o f ~ W a k e ~ F o r e s t ~ U n i v e r s i t y, ~ W i n s t o n-S a l e m, ~ N C ~ 27157, ~ U S A ~}$

\section{Author email addresses}

CDF: cfahrenh@wakehealth.edu; SD: dings0@wfu.edu; MY:yangm11@wfu.edu;

XY:yaox15@wfu.edu; BWB: bbernish@wakehealth.edu; MLW:

mariah.l.wright@alumni.wfu.edu; YZ: zheny9@wfu.edu; GLD: donatigl@wfu.edu; MDG:

grossmd@wfu.edu; UB: bierbau@wfu.edu

\section{Corresponding author}

* Ravi Singh, Ph.D., Assistant Professor, Department of Cancer Biology, Wake Forest School of Medicine, Hanes Bldg., Rm. 4045, Medical Center Blvd., Winston-Salem, NC 27157; Phone:

336-713-4434; FAX: 336-716-0255; Email: rasingh@wakehealth.edu 


\begin{abstract}
Athree-component drug-delivery system has been developed consisting of multi-walledcarbon nanotubes (MWCNTs) coated with anon-classicalplatinumchemotherapeutic agent([PtCl( $\left.\left.\mathrm{NH}_{3}\right)_{2}(\mathrm{~L})\right] \mathrm{Cl}$ (P3A1; L = N-(2-(acridin-9-ylamino)ethyl)- $N$ methylproprionimidamide)and 1,2-distearoyl-sn-glycero-3-phosphoethanolamine- $N$ [amino(polyethylene glycol)-5000] (DSPE-mPEG). The optimizedP3A1-MWCNTs are colloidallystable in physiological solution and deliver more P3A1into breast cancer cells than treatment with the free drug. Furthermore, P3A1-MWCNTsare cytotoxic to several cell models of breast cancer and induce S-phase cell cycle arrest and non-apoptotic cell death in breast cancer cells. By contrast,free P3A1induces apoptosisand allowsprogression to G2/M phase.Photothermal activation of P3A1-MWCNTsto generate mild hyperthermia potentiates their cytotoxicity. These findings suggest thatdelivery of P3A1to cancer cells using MWCNTs as a drug carriermay be beneficial for combination cancer chemotherapy and photothermaltherapy.
\end{abstract}

KEY WORDS: nanoparticle; chemotherapy; triple negative breast cancer; cytotoxicity; photothermal therapy; drug delivery 


\section{INTRODUCTION}

Platinum-based chemotherapeutic drugs such as cisplatin are among the most effective agents available to clinicians for treatment of testicular and ovarian cancer, but have limited ability to prolong survival of breast, colorectal, prostate, or lung cancer patients.[1]This is in large part due to the development of drug resistance and significant toxic side effects,which limit the ability to give patients the drugs at sufficient doses.[2]Second- and third-generation platinum chemotherapeutics such as carboplatin and oxaliplatinshow reduced toxic side effects, but intrinsic resistance in many types of cancer and acquired cross-resistance to therapy still limit their efficacy.[1] Resistance to these platinum agents occurs through tolerance of drug-induced DNA damage, insufficient DNA binding, poor drug uptake and increased activity of cellular detoxification pathways.[2]Cisplatin, carboplatin, and oxaliplatin all induce the same type of DNA damageand suffer from cross-resistance.[1, 2]

Recently developed platinum-acridine(PA) hybrid anticancer agents show a potential for cancer cell killing that is far superior to cisplatin.[3, 4]The acridine group functions as a DNA intercalator that when combined with a platinum moiety,leads to rapidmono-adduct formation with nucleotidesnear the intercalation site resulting in a moresevere form of DNA damage than the cross-links induced by cisplatin.[3-9]PAsalso form permanent adducts at significantly higher frequency in genomic DNA than cisplatin resulting in effective inhibition of DNA replication and transcription,[6]which results insubmicromolar activity against intrinsically platinumresistant cancers, including breast cancer,in vitro.[3, 10]Second-generation platinum-acridines are less reactive with non-DNA intracellular nucleophiles, which may contribute to their high potency .[11]The non-crosslinking DNA damage differs greatly from current clinical agents and is able to circumvent resistance.[3] 
Nanoparticles such as liposomes or polymer-based products are being tested in clinical trials to improve tumor delivery and reduce off-target toxicity of platinum drugs (reviewed in ref. [12]). Carbon nanotubes (CNTs), which consist of sheets of $\mathrm{sp}^{2}$ hybridized carbon rolled into single (SWCNT) or multi-walled (MWCNT) tubes, also show promise for the delivery of cisplatin to cancer cells both in vitro and in vivo.[13-19]CNTs have the capacity to cross biological barriers like the cell membrane,[20] improve the blood stability and tumor targeting of encapsulated or conjugated drugs and small molecules,[21-23] and overcome drug resistance.[24] In addition, the unique combination of electrical, thermal, and spectroscopic properties of CNTs offers further opportunities for advances in the detection, monitoring and therapy of cancer that are not available with other drug carriers.[25]CNTs absorb near-infrared radiation (NIR) emitted from lasers, generating intense heatthat can be localized to tumors after single[25-27]or multiple rounds of NIR exposure.[28]This type of laser-based heat treatment represents a promising approach for the management of recurrent breast cancer.[2933]Functionalization of CNTs by acid-oxidation and polymer-coating can render CNTs safe for in vivo use[23, 34, 35] and addition of targeting ligandsmay increase tumor-specific uptake.[14, 21-23]

Use of CNTs to deliver chemotherapeutic compounds such as doxorubicin or rutheniumpolypyridyl complexes adsorbed onto CNTs by non-covalent $\pi$-stacking results in enhanced cancer cell killing in comparison to the free drug.[24, 36]Acridine also strongly adsorbs onto the surface of CNTs and is released allowingintercalation into DNA.[37, 38]CNTs have a large surface area-to-volume ratiowhich allows high capacity drug loading.[39]Inspired by the welldocumented ability of CNTs to act as a strong adsorbent of cationic dyes,[40] we aimed to generate a CNT-based delivery system for a specific platinum-acridine,P3A1,[4, 41]that could 
combine the high cytotoxic activity of P3A1 with the drug delivery and photothermaltherapy capabilityof CNTs.

\section{EXPERIMENTAL}

Cell lines and reagents. The human breast cancer cell lines MDA-MB-231, MDA-MB-468, MDA-MB-436, SUM159, and BT20 were obtained from American Type Culture Collection (ATCC). All cell lines were authenticated by ATCC and tested to be pathogen-free (including Mycoplasma, bacteria, and fungi). All cells were used within 6 months of resuscitation. MDAMB-231, MDA-MB-468, SUM159, and BT20 were maintained as previously described.[42] MDA-MB-436 were maintained in Dulbecco’s Modified Eagle’s Medium (DMEM) supplemented with 10\% fetal bovine serum (Sigma Aldrich), $100 \mathrm{IU} / \mathrm{ml}$ penicillin (Life Technologies), and $100 \mu \mathrm{g} / \mathrm{ml}$ streptomycin (Life Technologies).

Synthesis.Compound P3A1 ([PtCl( $\left.\left.\mathrm{NH}_{3}\right)_{2}(\mathrm{~L})\right] \mathrm{Cl}$ (L = N-(2-(acridin-9-ylamino)ethyl)-Nmethylproprionimidamide) was synthesized according to a previously reported procedure [41] and isolated as the monochloride salt with an analytical purity of 96\% (based on LC-MS; see the Supplementary Figure S1).

Preparation of P3A1-loaded carbon nanotubes. Multi-walled carbon nanotubes (Nanostructured and Amorphous Materials Inc.) were acid-oxidized using a sulfuric acid and nitric acid treatment (3:1 mixture) for 3 hours at $75^{\circ} \mathrm{C}$. The MWCNTs were collected on an Omnipore JV filter (0.1 $\mu \mathrm{M}$, Millipore) and washed with distilled water. To remove carbonaceous debris formed during the acid-oxidation process, the surfaceacidized MWCNTs were resuspended in sodium hydroxide (1.0 M), sonicated for 10 minutes, and stirred at room temperature for 30 minutes.[23] MWCNTs were again collected on a filter as above, washed with distilled water and then 
resuspended in hydrochloric acid $(0.1 \mathrm{M})$ to protonate the carboxyl groups introduced during the oxidation process. After a final water washing and collection step, acid-oxidized MWCNTs were dried overnight at $80^{\circ} \mathrm{C}$. Stocks were prepared by dispersion of MWCNTs in water(4.5 mg/mL) by bath sonication. For drug loading experiments, P3A1-MWCNT[1] was prepared in a single step by adding acid-oxidized MWCNTs $(225 \mu \mathrm{g})$ to a glass vial containing saline, P3A1 (0-1.7 $\mu \mathrm{mol} / \mathrm{mg}$ MWCNT) and DSPE-mPEG (8.55 mg/mL). Similarly, P3A1-MWCNT[2] was prepared in two steps by adding acid-oxidized MWCNTs $(225 \mu \mathrm{g})$ to a glass vial containing P3A1 (0-1.11 $\mu \mathrm{mol} / \mathrm{mg}$ MWCNT) in saline. Finally, DSPE-mPEG was added to the dispersion at a final concentration of $8.55 \mathrm{mg} / \mathrm{mL}$. Each reaction mixture was bath sonicated twice for 15 minutes at $4^{\circ} \mathrm{C}$ to prevent overheating, and unbound P3A1and DSPE-mPEGwere separated usingspin columns (Vivaspin100kmolecular weight cut-off columns; EMD Millipore). For subsequent experiments, P3A1-MWCNT[1] or P3A1-MWCNT[2] were prepared by mixing the appropriate amounts of stock solutions of MWCNTs (400 $\mu \mathrm{L}, 1.8 \mathrm{mg})$, DSPE-mPEG(5000) (500 $\mu \mathrm{L}, 20 \mathrm{mg} / \mathrm{mLin}$ water, Nanocs), P3A1 (400 $\mu \mathrm{L}, 5 \mathrm{mM}$ in saline), and saline (10x, $124 \mu \mathrm{L}$ ), and mixtures were then sonicated as above. P3A1-containing materialsandplatinum-freecontrolswere incubated for 2 hours at $4^{\circ}$ C.Unassociated reagents were removed using a spin column as above. The final product was aliquoted and stored in saline at $-80^{\circ} \mathrm{C}$ until use.

Cytotoxicity Assays. 3-5 $\times 10^{4}$ breast cancer cells were plated in 96-well tissue culture plates (BD Falcon) and allowed to attach overnight. Cells were treated at doses indicated in the figures based on loaded P3A1and MWCNT concentration determined by UV-Vis spectroscopy as described in the supplementary information. An average of $0.84 \pm 0.06$ and $0.54 \pm 0.06$ $\mu \mathrm{mol} / \mathrm{mg}$ MWCNT was loaded for P3A1-MWCNT[1] and P3A1-MWCNT[2], respectively. 
Cells were incubated for the specified times and survival was assessed using theCellTiterGloassay kit (Promega) according to the manufacturers protocol. Nanoparticle Tracking Analysis. DSPE-mPEG coated MWCNTs, P3A1-MWCNT[1] and P3A1-MWCNT[2] were diluted 1:5000 in degassed Type I water. Hydrodynamic diameters were obtained in quintuplicate using the Nanosight NS500 (Malvern Instruments; software version 3.1, camera level: 16, duration: seconds, threshold: 3).

Dynamic Light Scattering (DLS). Hydrodynamic diameter and $\zeta$-potential were measured using the ZetasizerNano ZS90 (Malvern Instruments; software version 6.34) at $25^{\circ} \mathrm{C}$ with automatic settings. MWCNTs were diluted to $15 \mathrm{ng} / \mathrm{mLfor}$ DLS in water or saline for measurements. Confocal Microscopy. MDA-MB-231 cells $\left(3.5 \times 10^{4}\right)$ were plated in 4-well chamber slides (Nunc), allowed to attach for 48 hours, and then treated with vehicle, MWCNT, P3A1-MWCNT, or P3A1 at 7.5 $\mu$ M P3A1 or equivalent MWCNT for 6 hours. Cells were washed twice in PBS, fixed in 4\% paraformaldehyde, mounted with hardset mounting medium (Vector Labs) and cover slips, and assessed by confocal microscopy (Excitation 372 nm, Emission 449-549 nm; direct interference contrast (DIC)).

Transmission Electron Microscopy.P3A1-MWCNT[1], P3A1-MWCNT[2] or control DSPEmPEG-coated MWCNT in water were pipetted ontocopper-coated formvar grids and then imaged using a Tecnai Spirit transmission electron microscope. MDA-MB-231 cells $\left(3.0 \times 10^{6}\right)$ were plated in 100-mm tissue culture dishes and allowed to attach overnight. Cells were treated with P3A1-MWCNT[1] (20 $\mu \mathrm{g} / \mathrm{mLMWCNT)}$ and incubated for the times indicated. Cells were prepared as previously described.[23]

Flow Cytometry. MDA-MB-231 cells $\left(0.75-2 \times 10^{6}\right)$ were plated in $100-\mathrm{mm}$ tissue culture plates (BD Falcon) and allowed to adhere overnight. Cellswere then treated with P3A1-MWCNT[1], 
P3A1, DSPE-mPEG coated MWCNT, P3A1-DSPE-mPEG, DSPE-mPEG, DSPE-mPEG coated MWCNT,P3A1-DSPE-mPEG, or saline at the specified concentrations for 48 and 72 hours. Cells were washed with PBS and co-stained with Annexin V (APC) and propidium iodide (BD Pharmingen) per the manufacturer's protocol. Briefly, cells were trypsinized, pelleted, washed twice with cold PBS, and then suspended in $1 \times$ Annexin V binding buffer at a concentration of $1 \times 10^{6} / \mathrm{mL} .1 \times 10^{5}$ cells were then mixed with Annexin $\mathrm{V}$ and incubated for 15 minutes at room temperature in the dark then 400 uLof $1 \times$ Binding Buffer with or without propidium iodide (2.0 $\mu \mathrm{g} / \mathrm{mL}$ ) was added, mixed, and samples were analyzed on the Accuri6 Flow Cytometer (BD Biosciences). Analysis of data was performed using FCS Express version 3 (De Novo Software). For cell cycle analysis, cells were treated as indicated, fixed in 50\% ice-cold ethanol, washed once in PBS, and then were treated with FxCycle PI/RNase staining solution (Life Technologies) per the manufacturer's protocol. Analysis was performed using ModFit software. Inductively coupled plasma mass spectrometry.MDA-MB-231 $\left(2.0 \times 10^{6}\right)$ cells were plated in 60$\mathrm{mm}$ tissue culture plates and allowed to attach overnight. Cells were then treated with saline, P3A1-MWCNT[1], or P3A1 (1 $\mu \mathrm{M})$ for 6 hours and then trypsinized, washed twice in PBS, pelleted, and stored at $-20^{\circ} \mathrm{C}$. Samples were digested with a mixture of $5 \% \mathrm{HCl}$ and $5 \% \mathrm{HNO}_{3}$ using a microwave-assisted digestion system (Ethos UP, Milestone, Sorisole, Italy). The digested samples were then diluted to a final acid concentration of $1 \% \mathrm{v} / \mathrm{v}$ before Pt determination by inductively coupled plasma mass spectrometry (ICP-MS). Trace metal grade $\mathrm{HCl}$ and $\mathrm{HNO}_{3}$ (Fisher, Pittsburgh, PA, USA), and distilled-deionized water (18 M $\Omega \mathrm{cm}$, Milli-Q ${ }^{\circledR}$, Millipore, Bedford, MA, USA) were used to digest the samples and prepare all solutions. Standard reference solutions used for calibration were prepared in $1 \% \mathrm{v} / \mathrm{v}$ acid $(0.5 \% \mathrm{HCl}$ plus $0.5 \%$ $\mathrm{HNO}_{3}$ ) from a $1000 \mathrm{mg} / \mathrm{L}$ Pt stock (SPEX CertPrep, Metuchen, NJ, USA). A tandem ICP-MS 
(8800 Triple Quadrupole, Agilent, Tokyo, Japan) equipped with a SPS 4 automatic sampler, a Scott-type double pass spray chamber operated at $2^{\circ} \mathrm{C}$, and a Micromist concentric nebulizer was used in all determinations. Helium gas ( $\geq 99.999 \%$ purity, Airgas, Colfax, NC, USA) was used in the ICP-MS's collision/reaction cell to minimize potential spectral interferences while monitoring the isotope ${ }^{195} \mathrm{Pt}$. Other relevant instrument operating conditions such as radio frequency applied power, sample depth, carrier gas flow rate, reaction gas flow rate, and the number of sweeps per replicate were $1550 \mathrm{~W}, 10.0 \mathrm{~mm}, 1.05 \mathrm{~L} / \mathrm{min}, 4.0 \mathrm{~mL} / \mathrm{min}$, and 100, respectively.

Western Blots. MDA-MB-231 cells were seeded $\left(2.5-5.0 \times 10^{5}\right)$ in $60-\mathrm{mm}$ tissue culture dishes (BD Falcon) and allowed to attach overnight. The following day cells were treated for the indicated times. Plates were washed two times with ice cold PBS and lysates harvested in MPER Mammalian Protein Extraction Reagent (Thermo Scientific) supplemented with protease inhibitors (Thermo Scientific). Protein content was quantified by BCA protein assay (Pierce). Protein $(40 \mu \mathrm{g})$ was separated using a 12\% SDS-PAGE gel (Biorad) and transferred to nitrocellulose membrane (Biorad). Membranes were probed with primary antibodies for cleaved-PARP (Cell Signaling Technologies, D64E10, diluted 1:1000 in 5\% milk in tris-buffered saline containing 0.1\% Tween-20 (TBS-T) and GAPDH (Cell Signaling Technology, D16H11, diluted 1:10,000 in 5\% milk in TBS-Tween). Then membranes were then probed with appropriate horse-radish peroxidase conjugated secondary antibodies (Cell Signaling Technology, diluted 1:1,000-5,000 in 5\% milk in TBS-Tween) and developed using an enhanced chemiluminescence detection system (Pierce) according to the instructions provided by the manufacturer. 
Carbon nanotube-mediated photothermal therapy.MDA-MB-231 cells were plated in 48-well plates in non-neighboring wells at a cell density of $2.5 \times 10^{4}$ per well and allowed to attach overnight. Medium was aspirated, replaced with phenol-red free RPMI supplemented with 10\%FBS, and treated as indicated. Cells were irradiated at a wavelength of $970 \mathrm{~nm}$ and an irradiance of $3 \mathrm{~W} / \mathrm{cm}^{2}$ using a K-Cube veterinary laser (K-Laser USA). Twenty-four hours later, relative viability was assessed using CellTiterGlo reagent according to the manufacturer's protocol.

\section{RESULTS}

Preparation and physicochemical characterization of P3A1-loaded nanotubes.

To test if MWCNTs can be coated with a platinum-acridine (PA) agent, we used thederivative P3A1 (Fig. 1a,i)([PtCl( $\left.\left(\mathrm{NH}_{3}\right)_{2}(\mathrm{~L})\right] \mathrm{Cl}(\mathrm{L}=N$-(2-(acridin-9-ylamino)ethyl)- $N$ methylproprionimidamide).MWCNTswere acid oxidized to generate carboxyl groups (approximately $15-17 \%$ as a percentage of overall MWCNT weight (Supplementary Fig. S2)) on their surface, and then base washed to remove adsorbed carbonaceous debris (Fig. 1a, ii).All MWCNTs used in this study were coated with1,2-distearoyl-sn-glycero-3-phosphoethanolamine$N$-[amino(polyethylene glycol)-5000](DSPE-mPEG) (Fig. 1a, iii) to further improve dispersibility and biocompatibility. Thermogravimetric analysis indicated that DSPE-mPEG coated MWCNTcontained approximately 75\% DSPE-mPEG by weight after purification from excess coating material (SupplementaryFig. S2).

We assessed two methods for preparingP3A1-loaded carbon nanotubes. For the first method, we used aone-step synthesis,in which P3A1, MWCNT, and DSPE-mPEG were mixed simultaneously. The resulting drug-loaded nanoparticles are referred to as P3A1-MWCNT[1]. 
To determine optimal drug loading conditions, P3A1-MWCNT[1] was prepared with fixed quantities of MWCNTand DSPE-mPEG in the presence of increasing concentrations of P3A1. After adsorption, P3A1 loaded onto MWCNTs was separated from unbound P3A1 and DSPEmPEG using size-exclusion columns. P3A1 that was not bound to nanoparticles remained in the filtrate, and the unbound drug concentration was determined spectrophotometricallyat an acridine-specific wavelength $\left(\lambda_{\max }=415 \mathrm{~nm}\right)$ to determine the amount of MWCNT-associated P3A1(Supplementary Fig. S3). The amount of P3A1 loaded onto P3A1-MWCNT[1] relative to the total P3A1 added to the dispersion is shown in Fig. 1b. The highest level of P3A1 was achieved at the highest input of P3A1 $(1.7 \mu \mathrm{mol} / \mathrm{mg}$ MWCNT).The ratio of drug input to drug loaded on MWCNTs (P3A1 loaded/P3A1 input) gradually decreased from 100\% at a P3A1input of $0.25 \mu \mathrm{mol} / \mathrm{mg}$ MWCNT to less than $50 \%$ at an input greater than $1.5 \mu \mathrm{mol} / \mathrm{mg}$ MWCNT,defining a saturation point.

We used a two-step procedureto prepare a second type of P3A1-coated carbon nanotubes, termed P3A1-MWCNT[2]. P3A1 was first mixed with MWCNTsand then washed using sizeexclusion columns to remove unassociated P3A1; in a second step, aqueous DSPE-mPEGwas added to theP3A1 and MWCNT mixture. Notably, mixing P3A1 and MWCNTs in the absence of DSPE-mPEG resulted in substantial aggregation and sedimentation of the MWCNTs. However, after coating with DSPE-mPEG in the second step, P3A1-MWCNT[2] readily dispersed in water following sonication.We found a bimodal loading profile for P3A1MWCNT[2]without apparent saturation at P3A1 to MWCNT ratios of up to $1 \mu \mathrm{mol} / \mathrm{mg}$ (Fig. 1c).

We next examined the size distribution and $\zeta$-potential of uncoated MWCNTs, DSPEPEG coated MWCNTs, P3A1-MWCNT[1], and P3A1-MWCNT[2] using nanoparticle tracking 
analysis (NTA) and dynamic light scattering (DLS). The results are summarized in Table 1 and representative NTA data are shown in Fig. 1d-f. NTA indicated that P3A1-MWCNT[1] exhibited a monomodal size distribution with uniform light scattering intensity that is nearly identical to DSPE-mPEG coated MWCNT prepared without P3A1. However, P3A1MWCNT[2] exhibited a broader size distribution with multiple peaks and a more heterogeneous light scattering intensity. DLS also showed that P3A1-MWCNT[2] possessed the largest hydrodynamic diameter in water. Significantly, no increase in the hydrodynamic diameter of P3A1-MWCNT[1] was observed when measured in saline instead of water, indicating that the nanoparticles did not aggregate at this ionic strength. No change in hydrodynamic diameter was seen after storage of P3A1-MWCNT[1] in saline for 10 days at room temperature (Supplementary Fig. S4) indicating that P3A1-MWCNT[1] resisted aggregation under these conditions. In contrast, P3A1-MWCNT[2] tended to aggregate in normal saline as noted by an increase in the hydrodynamic diameter within a few minutes of incubation, though they were more stable in comparison to the uncoated MWCNT (Table 1). The $\zeta$-potentials in water at $\mathrm{pH} 6$ for P3A1-MWCNT[1], P3A1-MWCNT[2], and DSPE-mPEG coated MWCNT were considerably less negative than uncoated MWCNTs due tothe expected partial charge shielding effects of DSPE-mPEG and P3A1.

We next imaged P3A1-MWCNT[1], P3A1-MWCNT[2], and drug freeDSPEmPEGcoated MWCNT by transmission electron microscopy (TEM). Electron-dense regions indicative of the platinum in P3A1 were observed near the MWCNT surface of both P3A1MWCNT[1] and P3A1-MWCNT[2] but not for DSPE-mPEG-coated MWCNT (Fig. 2a-f). For P3A1-MWCNT[1], platinum was evenly distributed along the nanotube in single or multiple layers, indicating that P3A1 may both stack on the nanotube surface and self-aggregate within 
the DSPE-mPEG layer. By contrast, forP3A1-MWCNT[2] areas of platinum-related high electron density were found in concentrated pockets. Numerous drug-free and drugencapsulating micellar vesicles were seen around P3A1-MWCNT[2] but none were found around P3A1-MWCNT[1]. The methods of preparation and structural characteristics of thusobtained nanoparticles are shown schematically in Fig. 2g.Because P3A1-MWCNT[1] exhibited superior colloidal stability and more homogenous drug loading as compared to P3A1MWCNT[2], we selected this formulation as our lead material for subsequent studies, with other constructs used only as comparative controls.Fourier-Transform Infrared Spectroscopy (FTIR) was performed to further characterize P3A1-MWCNT[1] and determine if association of P1A1 with the MWCNTs involves coordination of platinum to the surface carboxylates. However, peaks corresponding to bond stretching characteristic of both DSPE-mPEG and P3A1 were undetectable when the sample contained MWCNT (Supplementary Fig. S5). Further analysis using inductively-coupled plasma mass spectrometry (ICP-MS)confirmed the presence of platinum in P3A1-MWCNT[1] (Supplementary Fig. S6).

P3A1-loaded nanotubes release drug after being taken up by breast cancer cells We next quantified the stability of the coating ofP3A1onP3A1-MWCNT[1] overtime. When stored in saline at room temperature, 90\% of the P3A1that was initially associated with the MWCNTs(representing 100\% of drug input)remained associated with P3A1-MWCNT[1]and only $10 \%$ of the amount of drug loaded onto the MWCNTs was released after 10 days (Supplementary Fig. S7). Although the fraction of the drug released from the MWCNTs (relative to the total amount initially bound to the MWCNTs) remained a constant $10 \%$ over time, this may be reflective of a dynamic equilibrium between MWCNT-associated and free 
P3A1in saline. Both sodium dodecyl sulfate (SDS) or ethanol increase the release of P3A1 from MWCNTs following a brief incubation (Supplementary Fig. S7). For all subsequent experiments, P3A1 constructs were stored frozen at $-80{ }^{\circ} \mathrm{C}$ in saline to avoid undesireddissociationof the pharmacophore from the carrier. No changes in nanoparticle size orP3A1content were detected after multiple freeze-thaw cycles (data not shown).

We next evaluated the release of P3A1 from MWCNTs following uptake by cancer cells. MDA-MB-231 breast cancer cells were treated with P3A1, P3A1-MWCNT[1], DSPE-mPEG coated MWCNTor normal saline at equivalent dosesof P3A1or MWCNT.P3A1-MWCNT[1] were taken up by cancer cells and could be detected within cells by electron microscopy following treatment (Fig. 3a). The intrinsic blue fluorescence of the 9-aminoacridine chromophore of P3A1allowed detection of intracellular P3A1 using confocal fluorescence microscopy.[43] Photomicrographs show blue fluorescence indicative of the presence of P3A1 in both P3A1only and P3A1-MWCNT[1] treated cells (Fig. 3b). Despite exposure to an equivalent drug dose, P3A1-MWCNT[1] treated cells exhibited a lowerfluorescence intensity compared to P3A1-treated cells, which is most likely a consequence of partial quenching of acridine fluorescence in the formulation. By contrast, detection of intracellular platinum by ICPMS unequivocally confirmed that P3A1-MWCNT[1] had accumulated at a significantly higher level in cells than P3A1(Fig. 3c).

P3A1-loaded nanotubes are cytotoxic to breast cancer cells

An initial cytotoxicity assay was performed to assess the effect of dose and incubation time (24, 48, 72 h) on the cytotoxicity of P3A1-MWCNT[1] using MDA-MB-231 cells (Fig. 4a). P3A1MWCNT[1] was slightly, but significantly ( $p<0.05$; student's t-test)less cytotoxic than free P3A1in the concentration range5-20 $\mu \mathrm{M}$ after 24 hours and at all concentrations tested at 48 and 
72 hours.Both P3A1 and P3A1-MWCNT[1] were significantly ( $p<0.05$; student's t-test)more cytotoxic than drug-free, DSPE-mPEG coated MWCNTs at all concentrations and incubation times.Finally, P3A1-MWCNT[1] proved to be significantly more cytotoxic than P3A1MWCNT[2] (Supplementary Fig. S8).

P3A1-MWCNT[1] consists of multiple components, each of which potentially may contribute to the overall cytotoxicity of the construct. In order to determine which components played a role in the cytotoxicity of our P3A1drug delivery system, MDA-MB-231 breast cancer cells were treated for 48 hours with P3A1 alone, P3A1-MWCNT[1], P3A1-DSPE-mPEG, or a mixture of P3A1-DSPE-mPEG and drug-free DSPE-mPEG coated MWCNTs at equivalent P3A1 and MWCNT concentrations (Supplementary Fig. S8). As a control, cells also were treated with dispersions of drug-free DSPE-mPEGor DSPE-mPEG coated MWCNTs prepared using processing conditions identical to the drug loaded constructs. Drug-free DSPE-mPEG did not cause a cytotoxic effect, and DSPE-mPEG coated MWCNTs killed less than25\% of cellsat

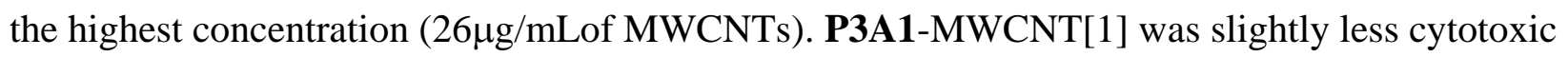
than respective free P3A1 at all concentrations tested, though substantially more cytotoxic than all other treatments.Importantly, P3A1-DSPE-mPEG was substantially less cytotoxic than P3A1-MWCNT[1], and the addition of drug free, DSPE-mPEG coated MWCNT did not alterthe cytotoxicity of P3A1-DSPE-mPEG, indicating that intact P3A1-MWCNT complex, rather than a treatment with a mixtureof the individual components, was important for the cytotoxicity of P3A1-MWCNT[1].

To further explore the potential use of P3A1-MWCNT[1] for cancer therapy, we exposed four additional breast cancer cell lines (MDA-MB-436, MDA-MB-468, SUM159 and BT20) to P3A1 alone, P3A1-MWCNT[1], or drug-free DSPE-mPEG coated MWCNT at equivalent doses 
of P3A1 or MWCNTs for 48 hours and quantified cell viability. P3A1-MWCNT[1]was similarly or slightly less cytotoxic than free P3A1toward all cell lines tested (Fig. 4b). The cytotoxicity of drug-free DSPE-mPEG coated MWCNT varied across cell lines tested, but was substantially lower than the levels observed for P3A1and P3A1-MWCNT[1]. The key finding in here is that substantial cytotoxic activity of P3A1 was retained after coating and release fromMWCNTs.

\section{P3A1-MWCNTsinduce a form of cell death that is distinct from the free drug}

Nanoparticle-based drug delivery systems can alter the way drugs are taken up by cells, how

drugs are released within cells, and how drugs distribute within cells. This in turn can affect the underlying pathways and mechanisms of cancer cell death induced by the nanoparticle-drug conjugate, which may differ substantially from the free drug.[44] Therefore, we examined the mechanism of cell death induced by P3A1-MWCNT[1] and free P3A1. MDA-MB-231 cells were treated with a fixed dose of P3A1-MWCNT[1] (12.5 $\mu \mathrm{g} / \mathrm{mLMWCNT;} 10 \mu \mathrm{M}$ P3A1),

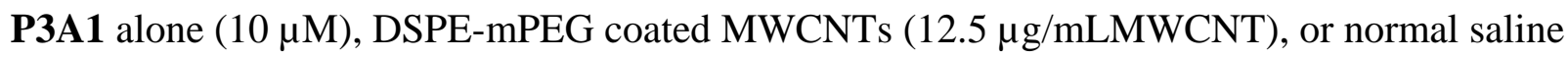
for 48 or 72 hours.Propidiumiodide (PI) and Annexin V (AnnV) co-staining followed by flow cytometric analysis was performed to allow discrimination between necrosis (PI+; AnnV-), early apoptosis (PI-; AnnV+), and late apoptosis (PI+; AnnV+). Thedataindicatethat free P3A1 and P3A1-MWCNT[1] induceddistinctly different mechanisms of cell death (Fig. 5a). P3A1induced apoptosiswas apparent at 48 hours, with increasingcell death (both early and late stage) at 72 hours compared to controls. Bycontrast, P3A1-MWCNT[1] showed a marked increase in necrosisat 48 and 72 hours without indications of early apoptosis.To confirm this finding we extracted protein from MDA-MB-231 cells treated with P3A1 or P3A1-MWCNT[1] as above 
for 24, 48 or 72 hours and quantified cleaved poly(ADP-ribose) polymerase 1 (PARP) by immunoblotanalysis (Fig. 5b). Cleavage of PARP isa hallmark of apoptosis and can also indicate necrosis.[45]Consistent with the PI/AnnV staining results, cleaved PARP was greatly increased in cells treated with P3A1 alone for 48 hours, but little was detected in cells treated with P3A1MWCNT[1] for 48 hours. After 72 hours, a high level of cleaved PARP was detected in cells following eithertreatment.

To gain insight into the cell cycle effects,additional flow cytometry experiments were performed. Cells treated with P3A1-MWCNT[1] inducedmarked S-phase cell cycle arrest (Fig. 5c). Increasing concentrations of P3A1-MWCNT[1]resulted in a loss of replicating cells, with the majority of the cells remaining in G1-phase after 48 hours of treatment. On the other hand, equivalent concentrations of P3A1 did not show a similar S-phase cell cycle arrest. Even when tested at high concentrations ( $80 \mu \mathrm{M})$, P3A1 did not show major alterations in cell cycle distribution. Together, these data suggest that P3A1-MWCNTscaused S-phase arrest and induced cell death by a non-apoptotic mechanism rather than an apoptotic mechanism, both of which are effects that are distinct from those induced by the free drug.

P3A1-loaded nanotubes are effective for multimodal photothermal therapy and drug delivery. Carbon nanotubes produce intense heat when stimulated with tissue-penetrating near-infrared (NIR) radiation[26, 27].Therefore we examined combined P3A1-MWCNT[1] treatment with photothermal therapy. MDA-MB-231 cells were treated with P3A1-MWCNT[1], control DSPEmPEG coated MWCNT, or vehicle, then exposed to $980 \mathrm{~nm}$ laser irradiation for thermal therapy. We found that P3A1-MWCNT[1] treatment sensitized cells to laser irradiation (3 W/cm²) (Fig. 6a). Control DSPE-mPEG MWCNT treatment did not induce a loss in cell viability after 60 
seconds of laser exposure, whereas P3A1-MWCNT[1] treated cells showed a significant reduction in viability under the same laser conditions. Importantly, this enhanced cytotoxicity occurred after only a brief exposure to mild, non-ablative hyperthermia. The maximum temperature reached after 60 seconds of exposure in the presence of P3A1-MWCNT[1] (or DSPE-mPEG coated MWCNTs) was only $44.2{ }^{\circ} \mathrm{C}$ (Fig. 6b).Following longer laser irradiation, the heat generated by the nanotubes alone was sufficient to kill most of the treated cells and was not further enhanced by loaded P3A1. Bycontrast, free P3A1 did not show any increase in cytotoxicity after laser irradiation (Supplementary Fig. S9). To assess whether laser irradiation and/or heat altered the release of P3A1 from P3A1-MWCNT[1], a sample of P3A1-MWCNT[1] was laser irradiated as above $\left(46^{\circ} \mathrm{C}\right)$. Laser irradiation marginally increased the proportion of P3A1 released from P3A1-MWCNT[1] to 11.9 \pm 0.2 of the total amount of P3A1 originally loaded onto the tube as compared to11.1 \pm 0.4 percent released from a non-irradiated sample of P3A1-MWCNT[1] processed in parallel.

\section{DISCUSSION}

The platinum-acridinederivative P3A1shows promising results for the treatment of intractable cancers bothin vitro and in rodent cancer models.[4]The key to further development of this and similar agents for clinical use will be to improve drug-like properties and reduce dose-limiting toxicities, while retaining anticancer activity.As a step toward the development of a more effective and selective therapeutic agent, we generated a MWCNT-based drug delivery system for P3A1. We showedthat P3A1readily coatsMWCNTsin the presence of DSPE-mPEG toform a colloidallystable nanoparticle complex. P3A1-MWCNT[1] deliveredmore P3A1to breast cancer cells than treatment with the free drug, were cytotoxic to several models of breast cancer, 
and induced a form of cytotoxicity that was distinct from the free drug and involvedboth S-phase cell cyclearrest and non-apoptotic cell death.Owing to the optical-thermal properties of the MWCNT backbone, P3A1-MWCNT[1] also enabledphotothermalcancer therapy.

Multiple groups have reported the use of CNTs and other fullerenes,[13-19] as well as liposomal and polymeric nanoparticles,[12, 46] for delivery of conventional platinum chemotherapeutics.In general, these previous studies focused on encapsulation of cisplatin or cisplatin derivatives within the lumen of CNTs as a strategy to prevent premature drug activation and for slow drug release following cell uptake.[13, 15-17] Alternatively, other CNT-based platinum chemotherapy delivery systems rely on covalent attachment to tether the functional platinum group to the CNT surface via a cleavable linker.[14, 18, 19]While these studies clearly demonstrate the capacity of using CNT for targeted drug delivery and controlled release, further clinical development may be hampered due to reliance on intracellular cleavage and modification of the platinum complex for activation, complicated linker synthesis, or inherent problems common to classical platinum pharmacophores.[1]Our system does not rely on activation of a prodrug and requires no modification of the drug for loading onto CNTs. In addition to $\pi$ stacking interactions,[37, 38, 47] electrostatic force between the negatively charged MWCNTs and positively charged P3A1, which exist as $2^{+}$charged cations at neutral $\mathrm{pH},[4]$ likely plays a role in the interaction of P3A1 with CNTs. Furthermore,the carboxylate groups on the MWCNTs may help further stabilize the platinum moieties via direct coordination.[48] P3A1-MWCNT[1] offers several potential advantages over previously described platinum therapeutic agents. First, we showed that P3A1-MWCNT[1]was effective for the treatment of five triple-negative breast cancer (TNBC) cell lines (Fig. 5) at a dose that is less than a tenth of the reported dose of cisplatin required for a similar effect on MDA-MB-231 
cells.[3]TNBC patients show the highest levels of tumor recurrence, the lowest five-year survival rates of all breast cancer subtypes,[49] and do not benefit from current molecularly targeted therapies.[50]The high activity we establish forP3A1 and P3A1-MWCNT[1] treatment of TNBC cells offers the possibility of expanding platinum therapy to TNBC patients.

We assessed two methods for preparing P3A1 loaded carbon nanotubes (P3A1MWCNT[1] and P3A1-MWCNT[1]) and noted a difference in P3A1 loading when assessed by electron microscopy.It appeared that the presence of DSPE-mPEG during loading of P3A1 onto P3A1-MWCNT[1] acted to stabilize the particle suspension against aggregation and allowed for a more even coating of P3A1. However, addition of P3A1in the absence of DSPE-mPEGinduced aggregation of P3A1-MWCNT[2] and the high drug concentration present on the surface of the nanotubes may have caused partitioning of P3A1 into DSPE-mPEG vesicles during the subsequent coating process. The micellar structures that appear on the surface of P3A1MWCNT[2] visualized by TEM may explain the larger hydrodynamic diameter and more heterogeneous size distribution of P3A1-MWCNT[2] as compared to P3A1-MWCNT[1].

We found that P3A1-MWCNT[1] inducedsevere replication stress which prevented cells from passing through S-phase and progressing through the cell cycle, leading to cell death without initiation of apoptosis; whereas free P3A1 induced apoptosis without a significant effect on progression through the cell cycle. P3A1-MWCNT[1] may be beneficial compared to free P3A1 as it immediately prevents breast cancer cells from dividing. Mutations or loss of the tumor suppressor p53, which is common in many cancers including TNBC,[51]can prevent induction of apoptosis.[52]We show that P3A1-MWCNT[1] induces non-apoptotic cell deathin a p53 mutant TNBC cell line, MDA-MB-231, and P3A1-MWCNT[1] was cytotoxic to threeadditional TNBC cell lines that harbor p53 mutations (BT20, MDA-MB-436, MDA-MB- 
468). These data suggest that P3A1-MWCNT[1] may be useful for treatment of cancers deficient in p53 or apoptotic machinery.

Serum or other components of the culture media could play a role in the extracellular release of P3A1, but the increased platinum delivery by P3A1-MWCNT and the different modes of cell death and cell cycle effects induced by free P3A1 and P3A1-MWCNT[1] suggest that the nanoparticle-drug conjugate is delivered intact to cells. Confocal fluorescence microscopy showed that cell-associated P3A1fluorescence intensity was lessforP3A1-MWCNT[1] treated cells compared to cells treated with free P3A1 at equivalent doses (Fig. 3b); however, cellassociated platinum assessed by ICP-MS was higher in P3A1-MWCNT[1]-treated cells compared to P3A1-treated cells (Fig. 3c). Because acridinefluorescence is quenched when associated with CNTs[38] and P3A1-MWCNT[1] delivers more platinum to cells in comparison to treatment of cells treated with an equivalent amount of free P3A1 (as shown by ICP-MS), it is reasonable to suggest that at least a portion of the P3A1 is still CNT-associated following cell uptake. CNTs may serve as a P3A1"reservoir" within in the cells. Therefore, the difference between the activity of P3A1 and P3A1-MWCNT[1] possibly lies within the delivery of the chemotherapeutic with regards to drug release, intracellulartrafficking and localization, maximal achieved dose, as well as dosing rate.

Thermal therapy shows promise for the treatment of many types of cancer.[29]Due to the MWCNT backbone, our drug delivery system has the inherent capability for combinationNIR stimulated photothermal therapy and P3A1 treatment. We show that photothermal activation of P3A1-MWCNT[1] is more effective than photothermal treatment of drug-free MWCNTs or P3A1-MWCNT[1] alone (Fig. 6). Importantly, this effect occursunder mild hyperthermia conditions $\left(44^{\circ} \mathrm{C}\right)$ and a brief exposure (60 seconds) to laser irradiation and therefore would be 
suitable as part of a treatment regimen designed to spare healthy breast tissue in a clinical setting.[30]We previously found that similar NIR exposure does not affect the cytotoxicity of MWCNT,[27, 28]. Thesmall increase in the amount of P3A1released following laser irradiation of P3A1-MWCNT[1] compared to drug release from non-irradiated P3A1-MWCNT[1] is likely insufficient to account for the increased cytotoxicity. Therefore this increase possiblyis caused by chemo-sensitization due to hyperthermia rather than greater drug release.[25]

The long-term rationale behind using nanoparticles, including CNTs, as drug delivery vehicles is the capacity for nanoparticles to accumulate in tumors at a higher rate than small molecules. This is due to the leaky and tortuous nature of tumor blood vessel architecture, a phenomenon known as the enhanced permeability and retention (EPR) effect.[53] Phospholipidpolyethylene glycol coated CNT, like those used in this report, can greatly increase blood residence and tumor selective delivery of small molecules and chemotherapeutics adsorbed onto their surface.[21-23]Acid-oxidation and polymer-coating can mitigate acute CNT toxicity in vivo,[23, 34, 35] and growing evidence suggests in vivo biodegradation mechanisms that could dramatically reduce any potential long-term risks of CNT exposure[54, 55]. CNTs are degraded within a few days by peroxidase enzymes from both plants and animals[56] and inside the cells by myeloperoxidase,[57]eosinophile peroxidase[58] or other reactive oxygen species mediated pathways.[55, 59] Moreover, enzymatically degraded CNTs appear to be less toxic as compared to their pristine counterparts.[57] As more understanding is developed regarding the degradation of CNTs in biological environments, it may be possible to design CNTs that leave no long-term biological footprint.[54]

\section{CONCLUSION}


Here we show the development of a new anti-neoplastic agent based upon a versatile MWCNT drug deliverysystem loaded with the chemotherapeutic agentP3A1,a platinum-based antineoplasticagent that is an order of magnitude more effective than current analogs.[3]The P3A1-MWCNT complex is easily formed in aqueous solution minimizing processing and purification steps, and enablescombined chemo- and photothermal therapy for multimodal cancer treatment regimens. The unique combination of tumor cell replicative stasis and non-apoptotic cell death induced by P3A1-MWCNT[1] may lead to improvements in cancer therapy usingP3A1 or similar drugs. Our system offers further possibilities for improved tumor accumulation, selective targeting, cancer imaging enabled by the MWCNT backbone.[25]We therefore believe that this agent warrants further preclinical investigation for the treatment of breast and other cancers. 


\begin{tabular}{|c|c|}
\hline \multicolumn{2}{|c|}{ ABBREVIATIONS } \\
\hline AnnV & annexin $\mathrm{V}$ \\
\hline CNT & carbon nanotube \\
\hline DLS & dynamic light scattering \\
\hline DMEM & Dulbecco's Modified Eagle's Medium \\
\hline DNA & deoxyribonucleic acid \\
\hline DSPE-mPEG & $\begin{array}{l}\text { 1,2-distearoyl-sn-glycero-3-phosphoethanolamine-N-[amino(polyethylene } \\
\text { glycol)-5000] }\end{array}$ \\
\hline EPR & enhanced permeability and retention \\
\hline FBS & fetal bovine serum \\
\hline FTIR & Fourier-transform infrared spectroscopy \\
\hline GAPDH & glyceraldehyde 3-phosphatase dehydrogenase \\
\hline ICP-MS & inductively coupled plasma mass spectometry \\
\hline MWCNT & multiwalled carbon nanotube \\
\hline NIR & near-infrared radiation \\
\hline NTA & nanoparticle tracking analysis \\
\hline P3A1 & ([PtCl(NH3)2(N-(2-(acridin-9-ylamino)ethyl)-N-methylproprionimidamide) \\
\hline $\mathrm{PA}$ & platinum-acridine \\
\hline PARP & poly ADP Ribose \\
\hline PBS & phosphate buffered saline \\
\hline PI & propidium iodide \\
\hline RPMI & Roswell Park Memorial Institute medium \\
\hline SWCNT & single walled carbon nanotube \\
\hline TBS & tris-buffered saline \\
\hline TEM & transmission electron microscopy \\
\hline
\end{tabular}




\section{ACKNOWLEDGMENTS}

This work was supported in part by grant NCI R00CA154006 (R.S.), by grant NCI R01CA101880 (U.B.) and by start-up funds from the Wake Forest School of Medicine Department of Cancer Biology. C.D.F was supported by NCI T32CA079448. We acknowledge support from the National Science Foundation's Major Research Instrumentation Program (NSFMRI, grant CHE-1531698) and from Wake Forest University Comprehensive Cancer Center (WFUCCC) Cellular Imaging Shared Resource and the Cell Viral Vector Core Laboratory supported in part by NCI CCSG P30CA012197. We also thank the National Institutes of Health and National Cancer Institute for grant 1R13CA200223-01A1 (Conference Organization support, $1^{\text {st }}$ International Symposium on Clinical and Experimental Metallodrugs in Medicine: Cancer Chemotherapy, CEMM), from which interesting discussions contributed to this work. We thank

Jessica Swanner, Jerod Sears, Brittany Eldridge, Ken Grant, Paula Graham, Yelena Karpova and Dr. David Ornelles of Wake Forest School of Medicine of Wake Forest University for assistance in data collection and analysis.

\section{AUTHOR CONTRIBUTIONS}

C.D.F., U.B. and R.S. conceived the research. C.D.F., S.D., M.Y., X.Y., B.W.B, M.L.W., Y.Z., M.D.G., G.L.D., U.B. and R.S. developed the methodology, carried out the experiments, and performed data analysis. C.D.F, U.B. and R.S. wrote the main manuscript text. All authors reviewed and edited the manuscript. 


\section{REFERENCES}

[1] L. Kelland, Nat Rev Cancer, vol. 7, 2007, pp. 573-584.

[2] L. Galluzzi, L. Senovilla, I. Vitale, J. Michels, I. Martins, O. Kepp, M. Castedo, G. Kroemer, Oncogene, vol. 31, 2012, pp. 1869-1883.

[3] L.A. Graham, J. Suryadi, T.K. West, G.L. Kucera, U. Bierbach, Journal of medicinal chemistry, vol. 55, 2012, pp. 7817-7827.

[4] Z. Ma, J.R. Choudhury, M.W. Wright, C.S. Day, G. Saluta, G.L. Kucera, U. Bierbach, Journal of medicinal chemistry, vol. 51, 2008, pp. 7574-7580.

[5] S. Dutta, M.J. Snyder, D. Rosile, K.L. Binz, E.H. Roll, J. Suryadi, U. Bierbach, M. Guthold, Cell biochemistry and biophysics, vol. 67, 2013, pp. 1103-1113.

[6] X. Qiao, A.E. Zeitany, M.W. Wright, A.S. Essader, K.E. Levine, G.L. Kucera, U. Bierbach, Metallomics : integrated biometal science, vol. 4, 2012, pp. 645-652.

[7] C.L. Smyre, G. Saluta, T.E. Kute, G.L. Kucera, U. Bierbach, ACS medicinal chemistry letters, vol. 2, 2011, pp. 870-874.

[8] L.A. Graham, G.M. Wilson, T.K. West, C.S. Day, G.L. Kucera, U. Bierbach, ACS medicinal chemistry letters, vol. 2, 2011, pp. 687-691.

[9] J.R. Choudhury, L. Rao, U. Bierbach, Journal of biological inorganic chemistry : JBIC : a publication of the Society of Biological Inorganic Chemistry, vol. 16, 2011, pp. 373-380.

[10] S. Ding, X. Qiao, G.L. Kucera, U. Bierbach, Chemical communications, vol. 49, 2013, pp. 2415-2417.

[11] Z. Ma, L. Rao, U. Bierbach, Journal of medicinal chemistry, vol. 52, 2009, pp. 3424-3427.

[12] H.S. Oberoi, N.V. Nukolova, A.V. Kabanov, T.K. Bronich, Advanced drug delivery reviews, vol. 65, 2013, pp. 1667-1685. 
[13] K. Ajima, T. Murakami, Y. Mizoguchi, K. Tsuchida, T. Ichihashi, S. Iijima, M. Yudasaka, ACS nano, vol. 2, 2008, pp. 2057-2064.

[14] S. Dhar, Z. Liu, J. Thomale, H. Dai, S.J. Lippard, Journal of the American Chemical Society, vol. 130, 2008, pp. 11467-11476.

[15] J. Li, A. Pant, C.F. Chin, W.H. Ang, C. Menard-Moyon, T.R. Nayak, D. Gibson, S.

Ramaprabhu, T. Panczyk, A. Bianco, G. Pastorin, Nanomedicine : nanotechnology, biology, and medicine, vol. 10, 2014, pp. 1465-1475.

[16] L. Muzi, C. Menard-Moyon, J. Russier, J. Li, C.F. Chin, W.H. Ang, G. Pastorin, G. Risuleo, A. Bianco, Nanoscale, vol. 7, 2015, pp. 5383-5394.

[17] S.L. Yoong, B.S. Wong, Q.L. Zhou, C.F. Chin, J. Li, T. Venkatesan, H.K. Ho, V. Yu, W.H. Ang, G. Pastorin, Biomaterials, vol. 35, 2014, pp. 748-759.

[18] A.A. Bhirde, V. Patel, J. Gavard, G. Zhang, A.A. Sousa, A. Masedunskas, R.D. Leapman, R. Weigert, J.S. Gutkind, J.F. Rusling, ACS nano, vol. 3, 2009, pp. 307-316.

[19] R.P. Feazell, N. Nakayama-Ratchford, H. Dai, S.J. Lippard, Journal of the American Chemical Society, vol. 129, 2007, pp. 8438-+.

[20] L. Lacerda, J. Russier, G. Pastorin, M.A. Herrero, E. Venturelli, H. Dumortier, K.T. AlJamal, M. Prato, K. Kostarelos, A. Bianco, Biomaterials, vol. 33, 2012, pp. 3334-3343.

[21] Z. Liu, K. Chen, C. Davis, S. Sherlock, Q. Cao, X. Chen, H. Dai, Cancer Res, vol. 68, 2008, pp. 6652-6660.

[22] W. Shao, A. Paul, B. Zhao, C. Lee, L. Rodes, S. Prakash, Biomaterials, vol. 34, 2013, pp. 10109-10119.

[23] C.D. Fahrenholtz, M. Hadimani, S.B. King, S.V. Torti, R. Singh, Nanomedicine (Lond), vol. 10, 2015, pp. 2481-2497. 
[24] N. Wang, Y. Feng, L. Zeng, Z. Zhao, T. Chen, ACS Appl Mater Interfaces, vol. 7, 2015, pp. 14933-14945.

[25] R. Singh, S.V. Torti, Advanced drug delivery reviews, vol. 65, 2013, pp. 2045-2060.

[26] S.V. Torti, F. Byrne, O. Whelan, N. Levi, B. Ucer, M. Schmid, F.M. Torti, S. Akman, J.

Liu, P.M. Ajayan, O. Nalamasu, D.L. Carroll, Int J Nanomedicine, vol. 2, 2007, pp. 707-714.

[27] B.N. Eldridge, B.W. Bernish, C.D. Fahrenholtz, R. Singh, ACS Biomaterials Science \& Engineering, American Chemical Society, 2016.

[28] X. Ding, R. Singh, A. Burke, H. Hatcher, J. Olson, R.A. Kraft, M. Schmid, D. Carroll, J.D.

Bourland, S. Akman, F.M. Torti, S.V. Torti, Nanomedicine (Lond), vol. 6, 2011, pp. 1341-1352.

[29] Z. Zhao, F. Wu, European journal of surgical oncology : the journal of the European Society of Surgical Oncology and the British Association of Surgical Oncology, vol. 36, 2010, pp. 11491155.

[30] K. Dowlatshahi, D.S. Francescatti, K.J. Bloom, American journal of surgery, vol. 184, 2002, pp. 359-363.

[31] J.L.R. Roti, Int J Hyperther, vol. 24, 2008, pp. 3-15.

[32] B. Emami, C.W. Song, Int J Radiat Oncol Biol Phys, vol. 10, 1984, pp. 289-295.

[33] A.R. Burke, R.N. Singh, D.L. Carroll, J.C. Wood, R.B. D'Agostino, Jr., P.M. Ajayan, F.M.

Torti, S.V. Torti, Biomaterials, vol. 33, 2012, pp. 2961-2970.

[34] R. Singh, D. Pantarotto, L. Lacerda, G. Pastorin, C. Klumpp, M. Prato, A. Bianco, K.

Kostarelos, Proc Natl Acad Sci U S A, vol. 103, 2006, pp. 3357-3362.

[35] A.R. Burke, R.N. Singh, D.L. Carroll, J.D. Owen, N.D. Kock, R. D'Agostino, Jr., F.M.

Torti, S.V. Torti, Biomaterials, vol. 32, 2011, pp. 5970-5978. 
[36] H. Ali-Boucetta, K.T. Al-Jamal, D. McCarthy, M. Prato, A. Bianco, K. Kostarelos, Chemical communications, 2008, pp. 459-461.

[37] Y. Meng, F.Y. Liu, J.F. Han, S.G. Sun, J.L. Fan, F.L. Song, X.J. Peng, Mater Sci Eng BAdv, vol. 177, 2012, pp. 887-891.

[38] N. Mackiewicz, J.A. Delaire, A.W. Rutherford, E. Doris, C. Mioskowski, Chemistry, vol. 15, 2009, pp. 3882-3888.

[39] M. Prato, K. Kostarelos, A. Bianco, Acc Chem Res, vol. 41, 2008, pp. 60-68.

[40] J.L. Gong, B. Wang, G.M. Zeng, C.P. Yang, C.G. Niu, Q.Y. Niu, W.J. Zhou, Y. Liang, J Hazard Mater, vol. 164, 2009, pp. 1517-1522.

[41] S. Ding, X. Qiao, G.L. Kucera, U. Bierbach, Journal of medicinal chemistry, vol. 55, 2012, pp. 10198-10203.

[42] J. Swanner, J. Mims, D. Carroll, S. Akman, C. Furdui, S. Torti, R. Singh, International Journal of Nanomedicine, vol. 10, 2015, pp. 3937-3953.

[43] A.J. Pickard, F. Liu, T.F. Bartenstein, L.G. Haines, K.E. Levine, G.L. Kucera, U. Bierbach, Chemistry, vol. 20, 2014, pp. 16174-16187.

[44] X. Li, Q. He, J. Shi, ACS nano, vol. 8, 2014, pp. 1309-1320.

[45] S. Gobeil, C.C. Boucher, D. Nadeau, G.G. Poirier, Cell Death Differ, vol. 8, 2001, pp. 588594.

[46] S. Dhar, F.X. Gu, R. Langer, O.C. Farokhzad, S.J. Lippard, Proc Natl Acad Sci U S A, vol. 105, 2008, pp. 17356-17361.

[47] C. Roquelet, J.S. Lauret, V. Alain-Rizzo, C. Voisin, R. Fleurier, M. Delarue, D. Garrot, A. Loiseau, P. Roussignol, J.A. Delaire, E. Deleporte, Chemphyschem, vol. 11, 2010, pp. 16671672. 
[48] H.Y. Lee, K.A. Mohammed, E.P. Goldberg, F. Kaye, N. Nasreen, Am J Cancer Res, vol. 5, 2015, pp. 603-615.

[49] R. Dent, M. Trudeau, K.I. Pritchard, W.M. Hanna, H.K. Kahn, C.A. Sawka, L.A. Lickley,

E. Rawlinson, P. Sun, S.A. Narod, Clin Cancer Res, vol. 13, 2007, pp. 4429-4434.

[50] C.A. Hudis, L. Gianni, Oncologist, vol. 16 Suppl 1, 2011, pp. 1-11.

[51] T. Sorlie, C.M. Perou, R. Tibshirani, T. Aas, S. Geisler, H. Johnsen, T. Hastie, M.B. Eisen, M. van de Rijn, S.S. Jeffrey, T. Thorsen, H. Quist, J.C. Matese, P.O. Brown, D. Botstein, P.E. Lonning, A.L. Borresen-Dale, Proc Natl Acad Sci U S A, vol. 98, 2001, pp. 10869-10874.

[52] J.S. Fridman, S.W. Lowe, Oncogene, vol. 22, 2003, pp. 9030-9040.

[53] J. Fang, H. Nakamura, H. Maeda, Advanced drug delivery reviews, vol. 63, 2011, pp. 136151.

[54] G.P. Kotchey, Y. Zhao, V.E. Kagan, A. Star, Advanced drug delivery reviews, vol. 65, 2013, pp. 1921-1932.

[55] D. Elgrabli, W. Dachraoui, C. Menard-Moyon, X.J. Liu, D. Begin, S. Begin-Colin, A. Bianco, F. Gazeau, D. Alloyeau, ACS nano, vol. 9, 2015, pp. 10113-10124.

[56] B.L. Allen, P.D. Kichambare, P. Gou, I.I. Vlasova, A.A. Kapralov, N. Konduru, V.E. Kagan, A. Star, Nano Lett, vol. 8, 2008, pp. 3899-3903.

[57] V.E. Kagan, N.V. Konduru, W.H. Feng, B.L. Allen, J. Conroy, Y. Volkov, I.I. Vlasova, N.A. Belikova, N. Yanamala, A. Kapralov, Y.Y. Tyurina, J.W. Shi, E.R. Kisin, A.R. Murray, J. Franks, D. Stolz, P.P. Gou, J. Klein-Seetharaman, B. Fadeel, A. Star, A.A. Shvedova, Nat Nanotechnol, vol. 5, 2010, pp. 354-359. 
[58] F.T. Andon, A.A. Kapralov, N. Yanamala, W.H. Feng, A. Baygan, B.J. Chambers, K. Hultenby, F. Ye, M.S. Toprak, B.D. Brandner, A. Fornara, J. Klein-Seetharaman, G.P. Kotchey, A. Star, A.A. Shvedova, B. Fadeel, V.E. Kagan, Small, vol. 9, 2013, pp. 2721-2729. [59] V.E. Kagan, A.A. Kapralov, C.M. St Croix, S.C. Watkins, E.R. Kisin, G.P. Kotchey, K. Balasubramanian, I.I. Vlasova, J. Yu, K. Kim, W. Seo, R.K. Mallampalli, A. Star, A.A. Shvedova, ACS nano, vol. 8, 2014, pp. 5610-5621. 


\section{TABLES}

\begin{tabular}{|c|c|c|c|c|c|c|}
\hline & $\begin{array}{c}\text { DLS }^{1} \\
\text { hydrodynamic } \\
\text { diameter in } \\
\text { water }\left(\mathrm{SD}^{2}\right)\end{array}$ & $\begin{array}{l}\text { Polydispersity } \\
\text { index in water } \\
\text { (SD) }\end{array}$ & $\begin{array}{c}\text { DLS } \\
\text { hydrodynamic } \\
\text { diameter in } \\
\text { saline (SD) }\end{array}$ & $\begin{array}{l}\text { Polydispersity } \\
\text { index in saline } \\
\text { (SD) }\end{array}$ & $\begin{array}{l}\zeta \text {-potential } \\
\text { (SD) }\end{array}$ & $\begin{array}{c}\text { NTA }^{3} \\
\text { hydrodynamic } \\
\text { diameter in } \\
\text { water (SD) }\end{array}$ \\
\hline $\begin{array}{l}\text { Uncoated } \\
\text { MWCNT }\end{array}$ & $\begin{array}{c}152.0 \mathrm{~nm} \\
( \pm 0.6)\end{array}$ & $\begin{array}{c}0.262 \\
( \pm 0.024)\end{array}$ & $\begin{array}{c}2826 \mathrm{~nm} \\
( \pm 390)\end{array}$ & $\begin{array}{c}0.572 \\
( \pm 0.038)\end{array}$ & $\begin{array}{c}-58.8 \mathrm{mV} \\
( \pm 4.6)\end{array}$ & $\begin{array}{c}171.5 \mathrm{~nm} \\
( \pm 1.8)\end{array}$ \\
\hline $\begin{array}{l}\text { DSPE-PEG } \\
\text { coated MWCNT }\end{array}$ & $\begin{array}{c}135.9 \mathrm{~nm} \\
( \pm 2.9)\end{array}$ & $\begin{array}{c}0.228 \\
( \pm 0.001)\end{array}$ & $\begin{array}{c}136.4 \mathrm{~nm} \\
( \pm 0.7)\end{array}$ & $\begin{array}{c}0.248 \\
( \pm 0.008)\end{array}$ & $\begin{array}{c}-17.4 \mathrm{mV} \\
( \pm 0.5)\end{array}$ & $\begin{array}{c}132.7 \mathrm{~nm} \\
( \pm 3.4)\end{array}$ \\
\hline $\begin{array}{l}\text { P3A1- } \\
\text { MWCNT[1] }\end{array}$ & $\begin{array}{c}151.3 \mathrm{~nm} \\
( \pm 4.4)\end{array}$ & $\begin{array}{c}0.234 \\
( \pm 0.032)\end{array}$ & $\begin{array}{c}138.3 \mathrm{~nm} \\
( \pm 0.9)\end{array}$ & $\begin{array}{c}0.235 \\
( \pm 0.009)\end{array}$ & $\begin{array}{c}-12.7 \mathrm{mV} \\
( \pm 0.9)\end{array}$ & $\begin{array}{c}138.9 \mathrm{~nm} \\
( \pm 4.9)\end{array}$ \\
\hline $\begin{array}{l}\text { P3A1- } \\
\text { MWCNT[2] }\end{array}$ & $\begin{array}{l}187.0 \\
( \pm 1.4)\end{array}$ & $\begin{array}{c}0.230 \\
( \pm 0.003)\end{array}$ & $\begin{array}{c}226.0 \mathrm{~nm} \\
( \pm 1.4)\end{array}$ & $\begin{array}{c}0.273 \\
( \pm 0.011)\end{array}$ & $\begin{array}{c}-18.0 \mathrm{mV} \\
( \pm 0.5)\end{array}$ & $\begin{array}{l}168.6 \mathrm{~nm} \\
( \pm 2.5)\end{array}$ \\
\hline
\end{tabular}

Table 1: Physicochemical characterization of P3A1-MWCNT constructs.

${ }^{1}$ dynamic light scattering (DLS); ${ }^{2}$ standard deviation (SD); ${ }^{3}$ nanoparticle tracking analysis (NTA) 


\section{FIGURE LEGENDS}

Figure 1.Chemical Structures,quantification of drug loading onto MWCNTs and nanoparticle size distributions(A) Chemical structures of (i) platinum-acridineP3A1, (ii) acid-oxidized carbon nanotubes, and (iii) 1,2-distearoyl-sn-glycero-3-phosphoethanolamine- $N$-[amino(polyethylene glycol)-5000] (DSPE-mPEG) are shown.(B)P3A1-MWCNT[1] or (C)P3A1-MWCNT[2] was prepared and unbound P3A1 was separated by size exclusion columns. Data are displayed as input P3A1 compared to MWCNT loaded P3A1 and calculated as $\mu$ molP3A1 per mg MWCNT. The hydrodynamic size distributions of (D) DSPE-mPEG coated MWCNT, (E) P3A1MWCNT[1] and (F) P3A1-MWCNT[2] were assessed by Nanoparticle Tracking Analysis (NTA).

Figure 2.Representative TEM images of drug loaded nanotubesElectron micrographs of (A) DSPE-mPEG coated MWCNT, (B-D) P3A1-MWCNT[1], and (E-F) P3A1-MWCNT[2](scale bar $=100 \mathrm{~nm}$ ) are shown. WHITE ARROWs indicate some areas of electron dense platinum (P3A1) bound to MWCNTs. BLACK ARROWs indicate aggregates of P3A1andDSPE-mPEG not bound to MWCNTs. (G) A schematic summarizing the preparation and structures of the P3A1 nanoparticles is shown.

Figure 3.Evaluation of P3A1-MWCNT[1] uptake and drug release in cancer cells. (A) MDAMB-231 cells were treated with P3A1-MWCNT[1] (20 $\mu \mathrm{g} / \mathrm{mLMWCNT})$ for 16 hours, fixed with glutaraldehyde, and prepared for TEM. Images of P3A1-MWCNT[1](white arrows) internalized by breast cancer cells are shown.Numbered regions in the lower magnification image $(30,000 x$; scale bar $=500 \mathrm{~nm})$ are shown in higher magnification $(90,000 \mathrm{x}$; scale bar $=$ 
$100 \mathrm{~nm}$ ) in the adjacent images. (B) MDA-MB-231 cells were treated with vehicle, drug-free DSPE-mPEG coated MWCNT, P3A1-MWCNT[1] or P3A1(7.5 $\mu$ M P3A1 or 9.8

$\mu \mathrm{g} / \mathrm{mLMWCNT}$ )for $6 \mathrm{~h}$, and then assessed for P3A1 fluorescence by confocal microscopy.(C) MDA-MB-231 cells were treated with vehicle, P3A1-MWCNT[1] or P3A1 (1.0 $\mu \mathrm{M})$ for $6 \mathrm{~h}$, harvested, microwave-assisted digested, analyzed by ICP-MS, and cell-associated platinum content is shown.

Figure 4.Quantification of P3A1-MWCNT[1] induced cytotoxicityin breast cancer cells. (A) MDA-MB-231 were treated for 24, 48, and 72 h, or (B) MDA-MB-468, BT20, MDA-MB-436 or SUM159 were treated for 48 hwith P3A1-MWCNT[1], DSPE-mPEGcoated MWCNT (0-26 $\mu \mathrm{g} / \mathrm{mL})$, P3A1 (0-20 $\mu \mathrm{M})$, or equivalentdoses of P3A1-MWCNT[1]. Data are shown as relative viability assessed by CellTiterGlo assay compared to untreated control \pm SD.

Figure 5.Analysis of cell death mechanism and cell cycle of breast cancer cells treated with P3A1-MWCNT[1]. (A) MDA-MB-231 were treated with drug free DSPE-mPEG coated MWCNT (12.5 $\mu \mathrm{g} / \mathrm{mL})$, P3A1 $(10 \mu \mathrm{M})$, or equivalent dose of P3A1-MWCNT[1] for 48 and 72 hours. Cells were co-stained with propidium iodide (PI) and Annexin V (AnnV), and then staining was assessed by flow cytometry. Data shown are representative of 3 independent experiments.(B) Lysates collected from cells treated as in (A) were probed by Western Blot for cleaved PARP (cl-PARP) following treatment for 24, 48 or 72 hours. GAPDH was used as a loading control. (C)MDA-MB-231 cells were treated with P3A1 (0-80 $\mu \mathrm{M})$, P3A1-MWCNT[1]

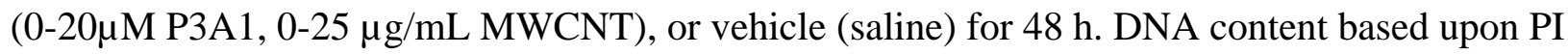
staining was assessed by flow cytometry. 
Figure 6.Evaluation of P3A1-MWCNT[1] for multimodal drug delivery and photothermal therapy.(A) MDA-MB-231 were treated with DSPE-mPEG coated MWCNT (12.5 $\mu \mathrm{g} / \mathrm{mL})$, P3A1-MWCNT[1] (12.5 $\mu \mathrm{g} / \mathrm{mL}, 10 \mu \mathrm{M}$ P3A1) or vehicle in dye free medium, then laser irradiated $\left(970 \mathrm{~nm}, 3 \mathrm{~W} / \mathrm{cm}^{2}\right)$ for the indicated times. Treatment efficacy was assessed by CellTiterGlo assay 24 hours later. Data are expressedas relative viability compared to untreated control $\pm \mathrm{SD}\left({ }^{* *} p<0.01\right.$, Two-tailed Student’s t-test).(B) Temperature was assessed by thermocouple immediately after laser irradiationin parallel samples treated as in (A). 